\title{
Tolerance to low-digestible carbohydrates: symptomatology and methods
}

\author{
Philippe Marteau ${ }^{1}$ and Bernard Flourié ${ }^{2}$ \\ ${ }^{1}$ Gastroenterology Department, European Hospital Georges Pompidou, 75015 Paris, France \\ ${ }^{2}$ Gastroenterology Department, Centre hospitalier Lyon-Sud, 165 chemin du Grand Revoyet, 69495 Pierre Bénite, France
}

\begin{abstract}
Low-digestible carbohydrates (LDCs) are incompletely or not absorbed in the small bowel and fermented in the colon. They are usually well tolerated but may also have some dose-related undesirable effects due to their natural osmotic potential and/or excessive fermentation: borborygmi, excessive flatus, bloating, abdominal cramps and eventually diarrhoea. There is an important intersubject variability in the tolerance to LDCs because of differences in absorption capacity, motility pattern, colonic response and intestinal sensitivity. There is also a great intrasubject variability, depending on the type of LDC, dosage and type of consumption. Absorption of LDC in the small intestine can be assessed using hydrogen breath test or intubation techniques or analysis of ileostomy effluents. Double-blind, placebo-controlled studies are required to assess the subjective symptoms of intolerance, and the experimental conditions may influence the results.
\end{abstract}

\section{LDCs: Polyols: Tolerance: Symptoms: Methods}

Low-digestible carbohydrates (LDCs) are incompletely or not absorbed in the small bowel; they may exert an osmotic effect in the intestinal lumen, and are totally or partly fermented in the colon into short-chain fatty acids and gas. They include for example, lactose in lactose maldigesters, polyols, resistant starch, non-starch polysaccharides, fructo-oligosaccharides, etc. They are present in food but also used in functional food products or as pharmaceuticals (van Loo et al. 1999). LDCs influence the endogenous ecosystem; they decrease colonic $\mathrm{pH}$, and some of them increase the population of bifidobacteria (McFarlane \& Cummings, 1999; van Loo et al. 1999). Relevant therapeutic effects have been obtained using lactulose, lactose and lactitol for the treatment of constipation and hepatic encephalopathy (Clausen \& Mortensen, 1997). Other applications such as colon cancer prevention, and effects of other LDCs have also been studied (Clausen \& Mortensen, 1997; Ponz de Leon \& Roncucci, 1997; van Loo et al. 1999). LDCs are usually well tolerated but may also have undesirable effects consisting of excessive flatus, borborygmi, abdominal pain and diarrhoea. We summarise and illustrate with examples the knowledge on the intolerance to LDCs, factors influencing it, and discuss the methods to assess it.

\section{Metabolism of LDC and clinical consequences}

LDCs differ in their composition and molecular weight but they are all either partly or totally malabsorbed in the small intestine. The two factors limiting absorption are the digestion of constitutive links by enzymes, and the passive absorption of small molecules. The degree of absorption of small LDCs varies depending on their flow rate in the small intestine; for example, that of sorbitol may vary from $2 \%$ to $80 \%$ (Beaugerie et al. 1990, 1996). As long as they are not absorbed, LDCs exert an osmotic effect in the intestinal lumen which is negatively related to their molecular weight. This increases the water flow rate, and may induce borborygmi, abdominal pain, and eventually diarrhoea if the capacity of the colon to absorb water and electrolytes is exceeded. Fermentation produces gas which may also induce borborygmi, abdominal pain and excessive flatus, but it decreases or may even suppress diarrhoea by removing the osmolarity (Rambaud \& Flourié, 1994). Intolerance symptoms can be due to the osmotic effect and/ or fermentation, and can originate from the small bowel and/or the colon. As a rule, the first symptoms occurring are borborygmi and excessive flatus; painful symptoms, i.e. bloating and cramps, occur for higher doses, and diarrhoea is always the last intolerance symptom occurring with high doses (Fig. 1). The protective role of colonic fermentation in reducing the severity of LDC-induced diarrhoea has been demonstrated in studies comparing the output of faecal water in response to a non-fermentable osmotic load such as polyethylene glycol (PEG) or magnesium sulphate with a load of LDC. Hammer et al. (1989) compared diarrhoea resulting from increasing iso-osmolar loads of polyethylene glycol (PEG) and lactulose. Lactulose induced less diarrhoea than PEG, especially at doses below $45 \mathrm{~g} / \mathrm{d}$. Saunders \& Wiggins (1981) showed that whereas increasing doses of magnesium sulphate immediately increased faecal output, a 'lag period' was observed with LDCs

\footnotetext{
* Corresponding author: Philippe Marteau, fax +33 1 44396799, email philippe.marteau@Inc.ap-hop-paris.fr
} 


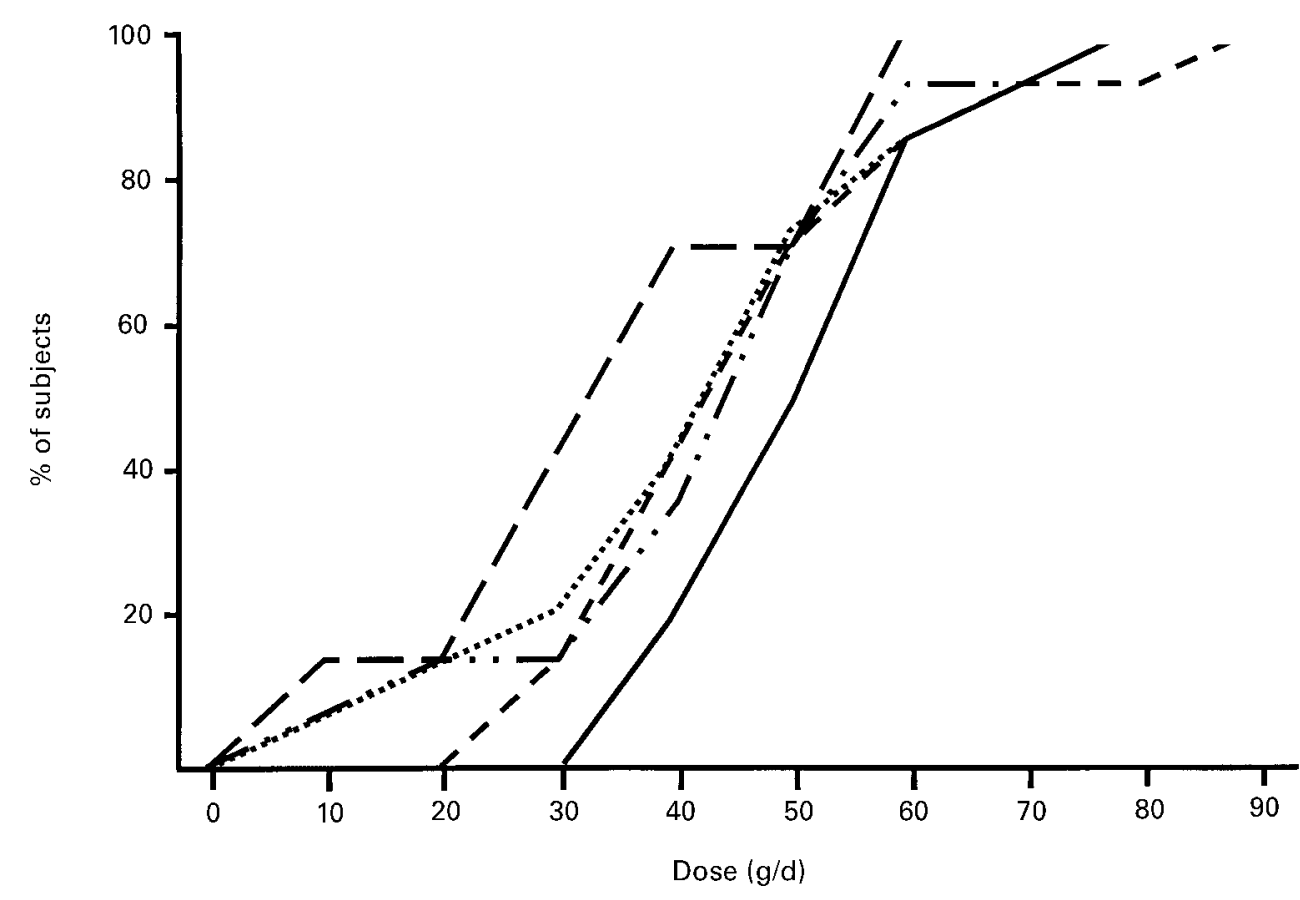

Fig. 1. Percentage of subjects reporting subjective symptoms at various doses of fructooligosaccharides consumed occasionally in hard candies (From Briet et al. 1995). —— Diarrhoea; --, cramps; ..., bloating; - .. - , borborygmus; —- flatus.

(mannitol, raffinose and lactulose). This lag period is probably largely due to fermentation of the LDC which suppresses a part of the osmotic force. The maximal capacity of the colonic flora to ferment various LDCs was estimated to be around $40-80 \mathrm{~g} / \mathrm{d}$. However, the lag period may also be due to an extensive storage capacity of the distal colon for non-absorbable fluid loads in some individuals (Hammer et al. 1997).

\section{Factors influencing the tolerance to LDC}

\section{Nature of LDCs}

LDCs differ concerning their degree of absorption, fermentation, and osmotic effect. Many studies have shown that the metabolism and/or tolerance (especially the laxative threshold) can vary between LDCs because of these characteristics. In the study by Koutsou et al. (1996), there were significant differences in the reporting of symptoms following the consumption of isomalt, lactitol and maltitol incorporated into milk chocolate. The mean symptom score was higher for lactitol, intermediate for isomalt and lower for maltitol, and this is probably due to differences in the extent of digestion in the small intestine and dynamics of fermentation. Beaugerie et al. (1991) observed that malabsorption was significantly higher for lactitol $(84 \pm 14 \%)$ than for maltitol and isomalt (44 \pm 7 and $40 \pm 7 \%$, respectively). Clausen et al. (1998) gave to twelve subjects increasing doses of fructo-oligosaccharides or lactulose in a crossover design. These LDCs differ greatly in their osmotic force but not in their metabolism. Both LDCs at high doses induced a dose-dependent diarrhoea. The slope for lactulose was twice as high as for fructo-oligosaccharides, but iso-osmolar doses of both LDCs had the same effects on faecal volume.

\section{Individual sensitivity factors}

Many studies have demonstrated that there is an important intersubject variability in the tolerance of LDCs which is probably due to differences in absorption capacities, motility patterns, colonic responses, and intestinal sensitivity. In the study by Clausen et al. (1998), lactulose at high doses induced a dose-dependent diarrhoea, but the variation in faecal volume was substantial. With $80 \mathrm{~g} / \mathrm{d}$, four out of twelve subjects were 'high responders' with more than 1 litre of diarrhoea, and four subjects were 'low responders' with faecal volumes below $280 \mathrm{ml} / \mathrm{d}$. It is likely that the difference in the dose-response between individuals was due to differences in the capacity for fermentation of the LDC. Indeed, when faecal samples from different subjects are incubated with the same LDC, the production of gas may vary in a 1/10 ratio (Hartemink et al. 1999). Variability of gaseous excretion has also been reported in human volunteers ingesting lactulose (Fume \& Levitt, 1996).

In the study by Patil et al. (1987) the laxative threshold of lactitol and sorbitol varied in healthy and adapted individuals between $40 \mathrm{~g} / \mathrm{d}$ and $130 \mathrm{~g} / \mathrm{d}$. Teuri et al. (1999) showed that the subjects with lactose maldigestion and those with self-reported milk intolerance were more often intolerant to low doses of fructo-oligosaccharides and lactulose than control lactose digesters. Suarez et al. (1997) reported that subjects with self-reported lactose intolerance had more gaseous symptoms than subjects who denied lactose intolerance, and that they had a different 


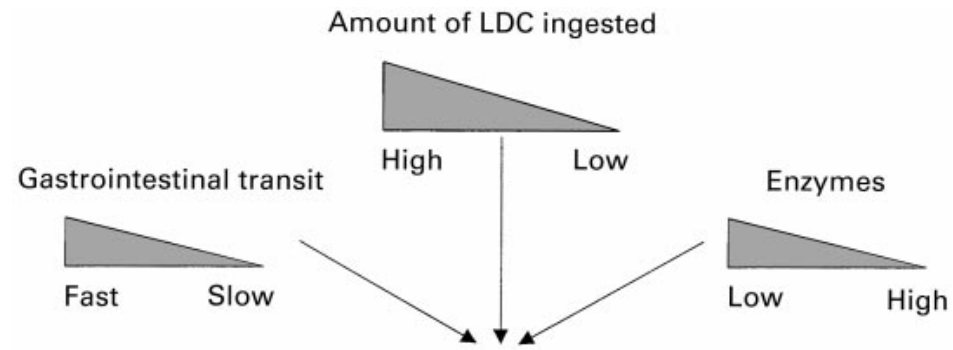

Amount of LDC malabsorbed

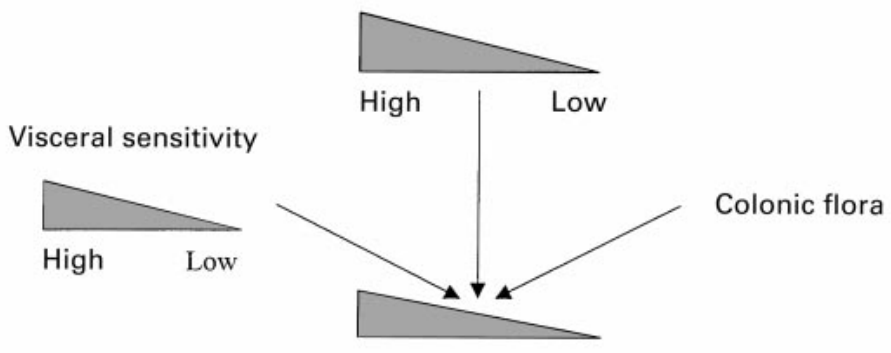

Symptoms intolerance

Fig. 2. Factors affecting LDC metabolism and tolerance. The high side of triangles indicates augmented, and the point, diminished malabsorption or symptoms.

psychological profile. Irritable bowel syndrome may contribute to the symptoms in subjects with LDC-intolerance (including lactose) (Rumessen \& Gudmand-Hoyer, 1988; Vesa et al. 1998).

\section{Dose dependency}

The risk of intolerance to LDCs and severity of symptoms in a given individual and in populations are clearly dose dependent (Hammer et al. 1989; Briet et al. 1995; Koutsou et al. 1996; Claussen \& Mortensen, 1997; Claussen et al. 1998; Bouhnik et al. 1999). A threshold is always found for diarrhoea, but not always for borborygmus or gaseousness as these symptoms are frequent in the general population even in the absence of consumption of LDCs (Fig. 1).

\section{Type of consumption}

The tolerance of the same LDC may vary in the same individual (and in groups of subjects) depending on the type of consumption. This can be explained by several mechanisms that do not exclude each other (Fig. 2). Intestinal absorption of low-molecular-weight LDCs can be modulated by factors affecting gastrointestinal behaviour. For example, the absorption of lactose may be enhanced when lactose is consumed in whole milk or yoghurt when compared to skim milk or when it is ingested together with fibres, a meal, cocoa or loperamide which slow down gastric emptying and/or intestinal transit (Marteau et al. 1997; Peuhkuri et al. 1999). Similarly, the degree of absorption of sorbitol was enhanced from $2 \%$ to $32 \%$ or $29 \%$ when a $20 \mathrm{~g}$ load was ingested together with $20 \mathrm{~g}$ of glucose or $9 \mathrm{~g}$ of lipids (Beaugerie et al. 1996). However, a difference in absorption and tolerance between LDCs consumed after fasting or with meals is not always observed (Storey et al. 1998).

Regular consumption of some LDCs such as lactose or lactulose results in changes in the metabolic activity of the colonic flora (bacterial adaptation) which increase its ability to ferment the sugar and include a fall in breath hydrogen excretion (Florent et al. 1985; Briet et al. 1997). Less diarrhoea might thus be expected when LDCs are consumed regularly (clinical adaptation). This was confirmed in some (but not all) human volunteers ingesting regularly low doses of lactulose (Flourié et al. 1993). However, the laxative effect of low doses of lactulose is not altered when this LDC is taken every day (Sobhani et al. 1996). Briet et al. (1995) reported that the symptoms and laxative threshold were similar during the occasional and regular consumption of fructo-oligosaccharides. No decrease in breath hydrogen excretion has been observed during chronic consumption of fructo-oligosaccharides, and it was hypothesised that this could be due to the absence of stimulation of the growth of lactic acid bacteria (StoneDorshow \& Levitt, 1987; Briet et al. 1995).

\section{Methods to assess metabolism and tolerance of LDCs}

\section{Absorption}

The most common method to assess the absorption of LDCs in the small intestine is the hydrogen breath test. Hydrogen in breath results from the bacterial fermentation. The hydrogen produced in the colon is partly absorbed into the blood and excreted through the lungs. The breath excretion of hydrogen is thus dependent on the fermentation profile of the flora, the substrate, the diffusion of hydrogen in the blood and the breath volume (Levitt et al. 1998). Breath hydrogen concentration is measured in a 
distinct time interval after ingestion of the LDC; the data are plotted in a graph and the total area under the curve is used as a measure for hydrogen production.

There is a high interindividual variation in hydrogen production. An individual estimate of the percentage of malabsorption may be made using the comparison with hydrogen production after ingestion of a given dose of lactulose (which is totally malabsorbed). Hydrogen formation has been observed after ingestion of most LDCs, and in most subjects. However, it should be kept in mind that a few subjects do not produce hydrogen, that hydrogen in breath is only a fraction of the total hydrogen produced, and that other gases are also produced. Another point is that different substrates may give rise to different amounts of hydrogen due to different stoichiometries (Hartemink et al. 1999).

The other methods to measure digestibility of LDCs in the small bowel are less often used and consist either of using intestinal intubation together with intestinal perfusion techniques (Beaugerie et al. 1990; Molis et al. 1996) or collecting the ileal fluid in ileostomists (Langkilde et al. 1994).

\section{Tolerance}

Breath tests do not assess tolerance. For example, less than $20 \%$ of lactose malabsorbers have symptoms when they drink $200 \mathrm{ml}$ of milk (Marteau et al. 1997; Suarez et al. 1997; Suarez \& Levitt, 1997). Tolerance therefore needs to be assessed by recording symptoms. These are similar with all LDCs and of the same nature as those experienced by individuals eating a normal mixed diet. Furthermore, they are often reported by subjects with irritable bowel syndrome.

As symptoms of intolerance vary widely between subjects, cross-over studies are preferable. It is then necessary to avoid carry over effects by choosing long enough wash-out periods (usually 2-3 weeks although longer periods may be proposed in order to give enough time for the colonic flora to recover after a diarrhoeal episode), and proper statistical tests to detect potential order effects. Subjects with irritable bowel syndrome are usually excluded. The volunteers are usually asked to avoid foods known to promote abdominal symptoms (beans, onions, cabbage, raisin, banana, apple, apricot, plum, wheat bran). One may argue that with the usual diet and in the general population, intolerance symptoms may be more frequent. However, it can be argued conversely that symptoms may be overestimated due to the unusual situation in which they are carefully recorded in clinical studies.

Subjects are asked to complete a diary card containing the following: occurrence of symptoms (excessive flatus, borborygmus, bloating, abdominal cramps), number of stools and consistency. Each symptom can be graded using a scoring system (for example none, mild, moderate or severe), or using a visual analogue scale. Symptoms are difficult to define as they are mostly subjective. The frequency of flatus emission can be measured (Fume \& Levitt, 1996). Bloating can be assessed objectively by measuring the abdominal girth. Diarrhoea can be assessed by weighing faeces, but is more often defined as 'one or more watery stool or more than three stools per day'. Such a definition has the advantage of being relatively easy to teach to a volunteer, but does not always properly assess the changes in bowel habits. Results can be expressed in different ways such as:

(1) the occurrence dose (threshold) for each symptom (which can be defined as the first dose from which a symptom is graded by a subject constantly higher with the LDC than with the placebo);

(2) the percentage of subjects who experience symptoms at a given dose of LDC;

(3) the mean score at a given dose of LDC;

(4) the $50 \%$ effective dose (which can be determined graphically for each symptom) (Hata \& Nakajima, 1985; Briet et al. 1995).

The type of LDC consumption (occasional or regular, after fasting or non-fasting) should be mentioned as it may influence tolerance. A placebo effect is often present, at least in studies performed in lactose-intolerant subjects, and the use of control periods, randomisation and blinded design is thus necessary (Briet et al. 1997; Suarez \& Levitt, 1997).

In summary, dose-related intolerance symptoms may occur after ingestion of LDCs. The dose for intolerance is often high, and the 'therapeutic window', i.e. the dose above the minimal effective dose and below the minimal not-tolerated dose is usually fairly broad. Double-blind placebo controlled studies are required, and the experimental conditions may influence the results. Symptom occurrence and severity vary according not only to the nature of the LDC and dose but also to the subject, and the type of consumption (Fig. 2).

\section{References}

Beaugerie L, Flourié B, Marteau P, Pellier P, Franchisseur C \& Rambaud JC (1990) Digestion and absorption in the human intestine of three sugar alcohols. Gastroenterology 99, 717723.

Beaugerie L, Flourié B, Pellier P, Achour L, Franchisseur C \& Rambaud JC (1991) Tolerance clinique, absorption intestinale et valeur energetique de quatre polyols pris a jeun. Gastroentérologie Clinique et Biologique 15, 929-932.

Beaugerie L, Lemann M, Jian R, Flourié B, Rain JD \& Rambaud JC (1996) Effect of glucose and lipids on intestinal absorption of sorbitol: role of gastric emptying. Neurogastrointestinal Motility 8, 235-239.

Bouhnik Y, Vahedi K, Achour L, Attar A, Salfati J, Pochart P, Marteau P, Flourié B, Bomet F \& Rambaud JC (1999) Shortchain fructo-oligosaccharide administration dose-dependently increases fecal bifidobacteria in healthy humans. Journal of Nutrition 129, 113-116.

Briet F, Achour L, Flourid B, Beaugerie L, Pellier P, Franchisseur C, Bomet F \& Rambaud JC (1995) Symptomatic response to varying levels of fructooligosaccharides consumed occasionally or regularly. European Journal of Clinical Nutrition 49, 501-507.

Briet F, Pochart P, Marteau P, Flourié B, Arrigoni E \& Rambaud JC (1997) Improved clinical tolerance to chronic lactose ingestion in subjects with lactose intolerance: a placebo effect? Gut 41, 632-635. 
Clausen MR \& Mortensen PB (1997) Lactulose, disaccharides and colonic flora. Clinical consequences. Drugs 53, 930-942.

Clausen NIR, Jorgensen J \& Mortensen PB (1998) Comparison of diarrhea induced by ingestion of fructooligosaccharide Idolax and disaccharide lactulose. Role of osmolarity versus fermentation of malabsorbed carbohydrate. Digestive Diseases and Sciences 43, 2696-2707.

Florent C, Flourié B, Leblond A, Rautureau M, Bemier JJ \& Rambaud JC (1985) Influence of chronic lactulose ingestion on the colonic metabolism of lactulose in man (an in vivo study). Journal of Clinical Investigation 75, 608-613.

Flourié B, Briet F, Florent C, Pellier P, Maurel M \& Rambaud JC (1993) Can diarrhea induced by lactulose be reduced by prolonged ingestion of lactulose? American Journal of Clinical Nutrition 58, 369-375.

Fume JK \& Levitt NW (1996) Factors influencing frequency of flatus emission by healthy subjects. Digestive Diseases and Sciences 41, 1631-1635.

Hammer HF, Santa Ana CA, Schiller LR \& Fordtran JS (1989) Studies of osmotic diarrhoea induced in normal subjects by ingestion of polyethylene glycol and lactulose. Journal of Clinical Investigation 84, 1056-1062.

Hammer J, Pruckmayer M, Bergmann H, Kletter K \& Gangl A (1997) The distal colon provides reserve storage capacity during colonic fluid overload. Gut 41, 658-663.

Hartemink R, Alles MS \& Rombouts FM (1999) Fermentation of selected carbohydrates by faecal inocula from volunteers on a controlled diet low in fibre. In: Prebiotic effects of nondigestible oligo- and polysaccharides. Thesis by Hartemink R. Landbouwuniversiteit Wageningen.

Hata Y \& Nakajima K (1985) Studies on relationship between intake of fructooligosaccharides and abdominal symptoms Estimation of the maximum non-effective dose and $50 \%$ laxative effective dose. Geriatric Medicine 23, 817-828.

Koutsou GA, Storey DM, Lee A, Zumbe A, Flourié B, Le bot Y \& Olivier Ph (1996) Dose-related gastrointestinal response to the ingestion of either isomalt, lactitol or maltitol in milk chocolate. European Journal of Clinical Nutrition 50, 17-21.

Langkilde AM, Andersson H, Schweizer TF \& Wursch P (1994) Digestion and absorption of sorbitol, maltitol and isomalt from the small bowel. A study in ileostomy subjects. European Journal of Clinical Nutrition 48, 768-775.

Levitt NW, Ellis C \& Fume J (1998) Influence of method of alveolar air collection on results of breath tests. Digestive Diseases and Sciences 43, 1938-1945.

Macfarlane GT \& Cummings JH (1999) Probioties and prebiotics: can regulating the activities of intestinal bacteria benefit health? British Medical Journal 318, 999-1003.

Marteau P, Vesa T \& Rambaud JC (1997) Lactose maldigestion. In Probiotics, pp. 65-88 [R Fuller, editor]. London: Chapman \& Hall.

Molis C, Flourié B, Ouame F, Gailing MF, Lartigue S, Guibert A, Bomet F \& Galmiche JP (1996) Digestion, excretion, and energy value of fructooligosaccharides in healthy humans. American Journal of Clinical Nutrition 64, 324-328.

Patil DH, Grimble GK \& Silk DBA (1987) Lactitol, a new hydrogenated lactose derivative: intestinal absorption and laxative threshold in normal human subjects. British Journal of Nutrition 57, 195-199.

Peuhkuri K, Vapaatalo H, Nevala R \& Korpela R (1999) Influence of the pharmacological modification of gastric emptying on lactose digestion and gastrointestinal symptoms. Alimentary Pharmacology and Therapeutics 13, 81-86.

Ponz de Leon M \& Roncucci L (1997) Chemoprevention of colorectal tumors: role of lactulose and of other agents. Scandinavian Journal of Gastroenterology Supplement 222, 72-75.

Rambaud JC \& Flourié B (1994) Mechanism of carbohydrateinduced diarrhoea. In Short Chain Fatty Acids, pp. 232-239 [HJ Binder, JH Cummings and K Soergel, editors]. Dordrecht: Kluwer Academic.

Rumessen JJ \& Gudmand-Hoyer E (1988) Functional bowel disease: malabsorption and abdominal distress after ingestion of fructose, sorbitol, and fructose-sorbitol mixtures. Gastroenterology 95, 694-700.

Saunders DR \& Wiggins HS (1981) Conservation of mannitol, lactulose, and raffinose by the human colon. American Journal of Physiology 241, G397-G402.

Sobhani I, Sansarricq M \& Flourié B (1996) Groupe d'lnvestigateurs d'lle-de-France (GIIF) Effect laxatif et tolérance du lactulose administré en une ou deux prises dans le traitement de la constipation chronique idiopathique. Gastroentérologie Clinique et Biologique 20, 362-366.

Stone-Dorshow T \& Levitt MD (1987) Gaseous response to ingestion of a poorly absorbed fructo-oligosaccharide sweetener. American Journal of Clinical Nutrition 46, 61-65.

Storey DM, Koutsou GA, Lee A, Zumbe A, Olivier P, Le Bot Y \& Flourié B (1998) Tolerance and breath hydrogen excretion following ingestion of maltitol incorporated at two levels into milk chocolate consumed by healthy young adults with and without fasting. Journal of Nutrition 128, 587-592.

Suarez F \& Levitt M (1997) Assessing food intolerance: don't lose control. Gut 41, 715-716.

Suarez FL, Savaiano D, Arbisi P \& Levitt NW (1997) Tolerance to the daily ingestion of two cups of milk by individuals claiming lactose intolerance. American Journal of Clinical Nutrition 65, 1502-1506.

Teuri U, Vapaatalo H \& Korpela R (1999) Fructooligosaccharides and lactulose cause more symptoms in lactose maldigesters and subjects with pseudohypolactasia than in control lactose digesters. American Journal of Clinical Nutrition 69, 973-979.

Van Loo J, Cummings J, Delzenne N, Englyst H, Franck A, Hopkins M, Kok N, Macfarlane G, Newton D, Quigley M, Roberfroid M, van Vliet T \& van den Heuvel E (1999) Functional food properties of non-digestible oligosaccharides: a consensus report from the ENDO project (DGXII AIRII-CT941095). British Journal of Nutrition 81, 121-132.

Vesa TH, Seppo LM, Marteau PR, Sahi T \& Korpela R (1998) Role of irritable bowel syndrome in subjective lactose intolerance. American Journal of Clinical Nutrition 67, 710715 . 